\title{
Analysis of the Spatiotemporal Distribution of Soil Organic Carbon
}

\author{
$\underline{\text { Kunkel, V. }}{ }^{\text {a }}$, G.R. ${ }^{\mathrm{a}}$ Hancock and T. Wells ${ }^{\mathrm{b}}$ \\ ${ }^{a}$ School of Environment and Life Sciences, The University of Newcastle, Australia \\ ${ }^{b}$ School of Engineering, The University of Newcastle, Australia \\ Email: veikko.kunkel@uon.edu.au
}

\begin{abstract}
Feedbacks between atmospheric and terrestrial carbon stocks remain unclear. Soil carbon stores are affected by a complex interaction among several biophysical and hydroclimatic processes, including the dynamics of soil moisture, insolation, and temperature. Studying the spatiotemporal distribution of soil organic carbon (SOC) and its dynamic changes is necessary for building a soil carbon pool inventory, as well as predicting the potential for soil carbon sequestration (Dorji et al., 2014). Many environmental controls on soil organic carbon have been analysed at site-specific plot-scales, while long term temporal studies of SOC dynamics are less common. The continued uncertainty of carbon cycle feedbacks, and the complexity of interactions of controls on, and transport of, soil carbon at regional scales, justifies further investigation. This study investigates the spatiotemporal relationships between surface SOC and a number of environmental variables across a catchment. The findings of this research will contribute to overall understanding of SOC distribution and controls for large regional scales.

The catchment for this study is located in the Upper Hunter Valley region of New South Wales, Australia. The study focuses on the Krui River catchment, having an area of $562 \mathrm{~km}^{2}$. Soil samples were obtained across the catchment using a $1 \mathrm{~km}$ grid scale. Cores with a depth of $220 \mathrm{~mm}$ were obtained from 59 grazing sites in 2006 and from 52 grazing sites in 2014, with 41 of the sites common to both 2006 and 2014. At each sampling location, aboveground biomass (AGB), soil moisture, and soil temperature was sampled within a $0.25 \mathrm{~m}^{2}$ quadrat. Land use at each sample site was classified as either cropping or grazing.
\end{abstract}

For a comparison of the temporal variability in SOC concentrations, average SOC from the two sampling dates were compared using Student's t-test. To determine which variables were the most important, principle component analysis was performed for topographic (elevation, slope, aspect, plan curvature, profile curvature, TWI), soil ( $\mathrm{pH}$, Electroconductivity, clay \%) and vegetation (sampled vegetation biomass, remotely sensed vegetation biomass) variables for the sample sites. SOC, elevation, Normalised Difference Vegetation Index (NDVI) and plan curvature were found to be the most important variables for the first 2 principle components. Linear regression and heteroscedasticity tests were applied to the strongest correlations between SOC and the other variables for both sampling periods.

The results of this study show that soil carbon was spatially and temporally stable over medium time scales (8+ years), with the variables of SOC, elevation and NDVI having strong, positive correlations with each other for both sampling periods. Strong, positive Pearson's $r$ correlations were observed between SOC and NDVI, a surrogate for Aboveground Net Primary Production (ANPP), for both sampling periods. Thus regions of higher net primary production corresponding with higher concentrations of SOC. Grazing intensity, represented in this study by sampled AGB, did not affect SOC.

Topography strongly influences vegetation via its control on such climate variables as precipitation and temperature. Elevation was found to explain much of the variability in NDVI, and hence SOC, although slope and aspect also had weak to moderate correlations with NDVI. The relationship between SOC and aspect was weak. This study demonstrates that the variables of elevation and NDVI can be used to digitally map the spatiotemporal distribution of SOC across large $\left(\sim 500 \mathrm{~km}^{2}\right)$ catchments of elevations ranging from $\sim 300$ to $\sim 1100 \mathrm{~m}$. However, long term seasonal climate variability may affect the predictive ability of SOC using these variables.

The spatial and long term temporal stability of catchment SOC demonstrated here has major implications for soil carbon sequestration. SOC across the catchment appears to be at equilibrium, with minimal variation observed after 8 years of continuous grazing. Carbon sequestration methods would therefore require major changes in grazing land-use to achieve observable increases in soil carbon.

Keywords: $\quad$ Soil temperature, catchment, geomorphology, NDVI 


\section{INTRODUCTION}

The exchange of carbon between agricultural soils and the atmosphere represents an important gap in our knowledge of global carbon cycling (Schimel et al., 2015). A small variation in soil C stores could lead to marked change in the $\mathrm{CO}_{2}$ concentration of atmosphere (Luo et al., 2010). Accurate estimates of the quantity and distribution of soil organic carbon (SOC) are therefore required for the ongoing monitoring of $\mathrm{C}$ sequestration (Dorji et al., 2014). Soil carbon stores are affected by a complex interaction among several biophysical and hydroclimatic processes, including the dynamics of soil moisture, insolation, and temperature. Predictive models and digital soil mapping have correlated many environmental variables with soil carbon at a range of spatial scales. Long term temporal studies of SOC dynamics are less common. This study investigates the spatiotemporal relationships between surface SOC and a number of environmental variables, including topographical attributes, vegetation attributes and soil attributes, across a $560 \mathrm{~km}^{2}$ catchment in the Upper Hunter region of NSW, Australia. This study will contribute to overall understanding of SOC spatiotemporal distribution and SOC controls at the regional scale $\left(\sim 500 \mathrm{~km}^{2}\right)$.

\section{METHODS}

\subsection{Description of Study Catchment}

The catchment for this study is located in the Upper Hunter Valley region of New South Wales, Australia. The study focuses on the Krui River catchment $\left(31^{\circ} 49^{\prime} \mathrm{S}\right.$ to $32^{\circ} 13^{\prime} \mathrm{S}, 150^{\circ} 02^{\prime} \mathrm{E}$ to $150^{\circ} 21^{\prime} \mathrm{E}$ ), hereafter Krui catchment. The Krui catchment covers an area of approximately $562 \mathrm{~km}^{2}$, and is located approximately 200 $\mathrm{km}$ north-west of Newcastle, situated between the townships of Merriwa (to the east) and Cassilis (to the west). The Krui is one of 12 major sub-catchments in the Goulburn River catchment $\left(6540 \mathrm{~km}^{2}\right)$ (Figure 1).

Catchment geology of the study area is dominated by Tertiary basalts, overlying Jurassic sandstone and shale which has been exposed to the south. Hence, the majority of soils across the Krui catchment have developed on basalt, resulting in deep, highly fertile soil profiles. The upper reaches of the catchment are dominated by Euchrozems. The Merriwa Plateau accounts for the majority of the soil landscape of the catchment, with Euchrozems and Chocolate Soils (Chromosols and Dermosols) found in the upper reaches of the plateau, and Black Earths (Black Vertisols) and Red Clays (Red Vertisols and Dermosols) found on mid to lower plateau slopes. The dominant land use is grazing, occurring on all soil

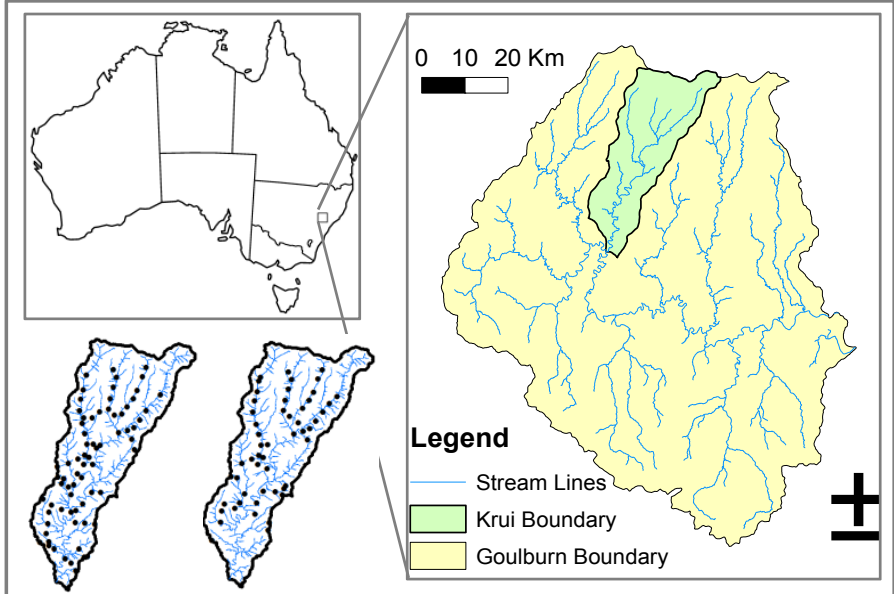

Figure 1. Location of the study catchment; and location of 2006 and 2014 sample sites.

types found in the catchment, while the majority of cropping occurring on black and red Vertisols. Average rainfall for the Goulburn catchment is $650 \mathrm{~mm}$. Precipitation varies significantly across the Krui catchment, associated with changes in altitude. Rainfall peaks on the Liverpool Ranges (approximately $1100 \mathrm{~mm}$ ), decreasing to its minimum on the Merriwa Plateau (approximately $400 \mathrm{~mm}$ ) (Rüdiger et al., 2007).

\subsection{Field Methods: Soil Surface Sampling}

The Krui catchment was sampled in April 2006, and again in June 2014 (Figure 1).

The goal of the 2006 campaign was to collect SOC data at a kilometre grid scale across the study catchment in order to provide a snapshot of SOC distribution over both grazing and cropping land. Final sample site selection was affected by accessibility. The 2006 campaign sampled 82 sites. Of these sample sites, 59 sites were classified as non-cropping land-use. For the 2014 sampling campaign, the decision was made to only sample grazing land-use. Thus, 52 grazing sites were sampled in June and July 2014. Of the 52 sites, 41 grazing sample sites were common to both 2006 and 2014 sampling campaigns (Figure 1). For spatiotemporal data analysis between the two sampling periods, the set of 41 sampling sites were used.

The sampling method at each sample site involved using a steel core of $220 \mathrm{~mm}$ depth and a diameter of $94 \mathrm{~mm}$. The core was fitted with a steel cap, which allowed it to be driven into the ground with a sledge hammer. In 
areas where maximum soil depth was less than $220 \mathrm{~mm}$ (e.g., on ridgetops), cores were instead taken to the maximum depth, with the difference in depth recorded. Once inserted to the desired depth, the core was removed either by excavation or by using vice-grips to twist the metal core from the ground. At each sampling location, above ground biomass (AGB), soil moisture, and soil temperature was sampled within a $0.25 \mathrm{~m}^{2}$ quadrat. Land use at each sample site was classified as either cropping or grazing.

\subsection{Preparation and Analysis of Soil Samples}

In preparation for laboratory analysis, soil samples were air-dried in a $40^{\circ} \mathrm{C}$ oven for at least 7 days. Coarse ( $>$ $2 \mathrm{~mm}$ ) fractions of each sample were disaggregated mechanically. The samples were then passed through a 2 $\mathrm{mm}$ sieve, with a subsample of $25 \mathrm{~g}$ of $<2 \mathrm{~mm}$ fraction used for particle size analysis, and subsamples of $20 \mathrm{~g}$ of $<2 \mathrm{~mm}$ fraction used for $\mathrm{pH} / \mathrm{EC}$ analysis and carbon analysis.

The subsamples for carbon concentration (\%) analysis were dried for a further 48 hours at $60^{\circ} \mathrm{C}$ and crushed to obtain a fine $(<0.5 \mathrm{~mm})$ powder. Soil samples of between $0.25-1.00 \mathrm{~g}$ were then mounted on a crucible and analysed in a LECO CNS2000 analyser. Soil carbon values resulting from the dry combustion analysis gives SOC concentrations as a percentage $\mathrm{C}$ mass to total soil mass.

Particle size analysis was undertaken primarily to determine soil texture in terms of \% clay content using the hydrometer method. A dispersant solution of $4 \%$ sodium polymetaphosphate [(NaPO3)6] and sodium carbonate [Na2CO3] (33 g sodium polymetaphosphate $+7 \mathrm{~g}$ sodium carbonate in $1000 \mathrm{~mL}$ of distilled water) was added to each subsample in a plastic Erlenmeyer flask with a screw-cap. The content of each flask were mechanically shaken for one hour. Following this, the soil-dispersant mixture was washed into a $1 \mathrm{~L}$ measuring cylinder and diluted to $1 \mathrm{~L}$ with distilled water. A plunger was used to agitate the contents of each cylinder prior to gently inserting a hydrometer and recording hydrometer levels at $0.5,0.66,0.8,1,2,4,6,8$, $10,30,60$ and 1440 minutes. In order to correct results dispersant/water viscosity, hydrometer readings of a blank dispersant/water and a water-only cylinder were taken. The temperature of the blank solution was recorded for temperature corrections. The hydrometer results were then used to create a grain size distribution curve, from which sand $(0.02-2 \mathrm{~mm})$, silt $(0.002-0.02 \mathrm{~mm})$ and clay $(0.002 \mathrm{~mm})$ fractions could be derived.

Soil $\mathrm{pH}$ was measured using an Oakton Acorn Series $\mathrm{pH}$ meter, calibrated using two standard solutions (pH 4, and pH 7). Soil EC was measured using a Eutech Ecoscan hand-held EC meter, calibrated using a $1440 \mu \mathrm{S}$ standard solution. For each soil core, a subsample of $20 \mathrm{~g}$ from the $<2 \mathrm{~mm}$ fraction was placed in an Erlenmeyer flask with $100 \mathrm{~mL}$ of distilled water. Samples were then agitated mechanically for one hour, and measurements taken using the appropriate probes.

\subsection{GIS and Remote Sensing Analysis}

Topographic features have been widely used to predict soil attributes such as SOC. Topographic controls over SOC were investigated using principle component analysis for both 2006 and 2014 sampled data. The topographic features investigated here were comprised of elevation, slope, aspect, profile curvature, plan curvature, and topographic wetness index (TWI). All topographical attributes were derived from a $25 \mathrm{~m}$ Land and Property Information (LPI) New South Wales Digital Elevation Model (DEM) using ArcGIS 10.0. Pitfilling was undertaken prior to the generation of topographical attributes in order to remove potential errors which may remain in the DEM after processing. Topographical attributes for each soil sampling site were extracted from the DEM using the GPS co-ordinates recorded at each sample site. A Topographical Wetness Index (TWI) map was calculated using the following equation, modified from Bevan and Kirkby (1979):

$$
T W I=\ln \frac{A_{s}}{\tan \left(B \times \frac{\pi}{180}\right)}
$$

where $A_{s}$ is the total upslope area of the cell in $\mathrm{m}^{2}$ and $\mathrm{B}$ is the slope of the cell.

Vegetation is known to have a strong influence on soil carbon cycling, where the rate of $\mathrm{C}$ input to the soil is related also to the productivity of the vegetation growing on that soil, measured by aboveground net primary production (ANPP). To compare the relationship between SOC and ANPP, NDVI was used as a surrogate for ANPP. The index is a normalised ratio of the near-infrared and visible red spectral bands:

$$
N D V I=\frac{\rho_{(N I R)}-\rho_{(R)}}{\rho_{(N I R)}+\rho_{(R)}}
$$

Low NDVI values represent lower levels of 'green' vegetation. 
Landsat remotely sensed imagery was used to quantify NDVI prior to sampling in both 2006 and 2014. For the period 2002-2006, Landsat 5 and Landsat 7 scenes were used. For 2013-2014, only Landsat 8 imagery was used due to issues with Landsat 7's Scan Line Corrector (SLC), and Landsat 5 had been decommissioned on June 5 2013. The Landsat satellite series has a spatial resolution of $30 \mathrm{~m}$.

NDVI obtained from the Moderate Resolution Imaging Spectrometer (MODIS) was also included for comparison. Global MODIS vegetation indices are designed to provide consistent spatial and temporal comparisons of vegetation conditions. Blue, red, and near-infrared reflectance, centered at 469-nanometers, 645-nanometers, and 858-nanometers, respectively, are used to determine the MODIS daily vegetation indices. MODIS has a spatial resolution of $250 \mathrm{~m}$.

Although the obtained SOC measurements are essentially static snapshots, SOC was assumed to be influenced by historical ANPP inputs of carbon, represented in this study by temporally averaged NDVI, prior to the sampling date.

A maximum Pearson correlation value between SOC and NDVI for both sampling periods was determined by comparing SOC to the range of temporally, cumulative averaged NDVI maps over multiple dates prior to the date of sampling (Figure 2). The SOC-NDVI relationship for both Landsat and MODIS data in 2006 stabilised after temporal averaging over 24 months. The SOC-NDVI relationship for Landsat in 2014 stabilised quickly, after 10 months, while MODIS took much longer to stabilize, if at all (Figure 2). Landsat attained a higher optimum SOC-NDVI relationship than MODIS for both sampling periods. This was attributed to the differences in resolution between Landsat and MODIS.

The set of NDVI values that produced the maximum Pearson correlation with SOC was included as the NDVI variable in the Principle Component Analysis.
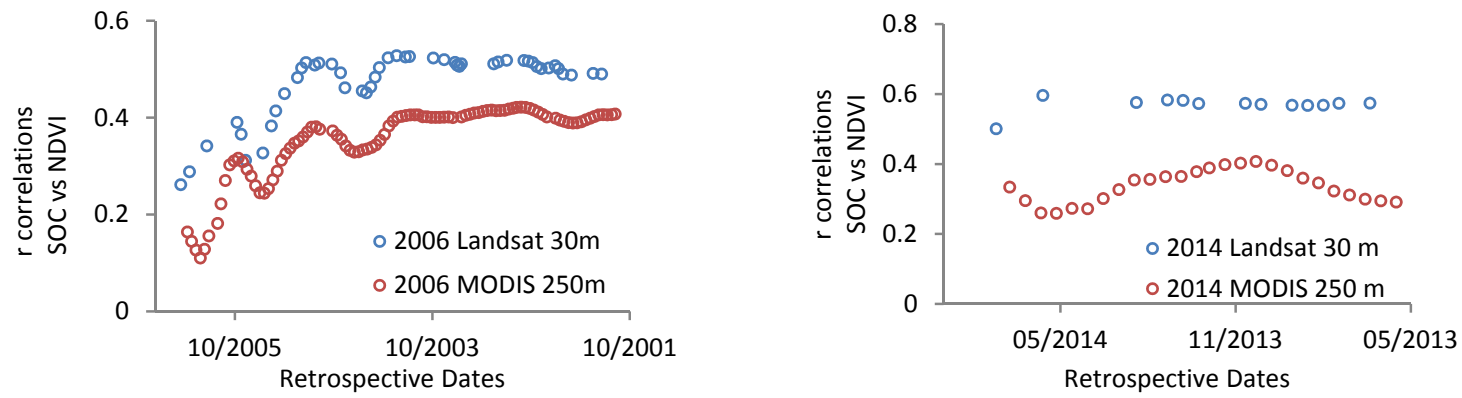

Figure 2. Temporal retrospective averaging of NDVI sampling improved the Pearson's r correlations between SOC and NDVI for both Landsat and MODIS, and for both sampling periods. Note: NDVI was temporally averaged over approximately 4 years of historical data prior to 2006 sampling, while NDVI was temporally averaged over 13 months of historical data, due to issues with Landsat platforms after 2013.

\subsection{Statistical Analysis}

SOC concentrations for the two sampling periods were compared using Student's t-test, to determine if there was a significant temporal change in carbon.

After the topographical, soil, and vegetation attributes were obtained for each site, principle component analysis (PCA) was used to determine the strongest correlations between those variables. To examine the potential of the influence of grazing land use on SOC, the dry weight $\%$ of sampled vegetation biomass was also included as a variable in the PCA. The assumption here is that sample sites with less vegetation dry weight $\%$ are likely to be more intensely grazed. Variables were standardized prior to PCA.

Linear regression analysis was performed for the strongest relationships between SOC and other variables. These relationships were also tested for heteroscedasticity using the Goldfeld-Quant test.

\section{RESULTS}

\subsection{Analysis of SOC}

Catchment-wide average SOC concentration was slightly lower in 2014 compared to 2006 (Table 1). Variability was also similar between the two sampling periods, with the standard deviation and Inter Quartile Range (IQR) being slightly lower for 2014 SOC. This indicates that SOC was potentially more stable across 
Kunkel, V. et al., Modelling the Spatial and Temporal Distribution of Soil Organic Carbon

the catchment in 2014 than in 2006. Student's t-test results showed that average SOC concentration (\%) was not significantly different between the two sampling campaigns $(\mathrm{t}(80)=1.99, \mathrm{P}=0.58)$.

Principle component analysis of the 12 soil variables resulted in 5 principle components (PCs) for 2006 and 4 principle components for 2014, where eigenvalues were $>1$.

The first 5 PCs for 2006 accounted for $75.2 \%$

of the variance in the data, while the first 4 PCs for 2014 accounted for $68.2 \%$ of the variance in data (Table 2 ).

For both 2006 and 2014, SOC, elevation, NDVI and profile curvature were the most important variables for the first two principle components. For 2006, the first principle component included SOC, elevation and NDVI as the dominant variables, where an increase in one matched increases in the other two.

For 2014, the trend was similar, with SOC, elevation and NDVI again having strong influence on the first principle

Table 1. Krui Catchment SOC concentration (\%) descriptive statistics 2006 and 2014 for grazing land use $(n=41)$.

\begin{tabular}{ccc}
\hline & 2006 & 2014 \\
\hline mean & 3.33 & 3.20 \\
SD & 1.13 & 0.92 \\
IQR & 1.40 & 0.78 \\
$\min$ & 1.88 & 1.95 \\
$\max$ & 6.89 & 6.45 \\
\hline
\end{tabular}
component, although NDVI was dominant, along with profile curvature, in the second principle component for 2014.

There were moderately strong and significant correlations for SOC with elevation, slope and NDVI for both 2006 and 2014 (Table 3), despite an 8+ year period between sampling.

The strong, positive correlation between SOC and elevation is attributed to the orographic effect, and hence the influence of elevation on vegetation, rather than on the potential for increased grazing intensity at lower elevations. Sample AGB, as an indicator of grazing intensity, had a poor correlation with SOC (Table 3). Furthermore, AGB was not an important factor in the PCA analysis for either sampling period (Table 2). It has been observed that on soils with high clay content, grazing has less positive or more strongly negative effects on SOC at higher precipitation (McSherry and Ritchie, 2013). Hence, more intense grazing at lower elevations, combined with lower precipitation, would have similar effects as less intense grazing and higher precipitation at higher elevations. Although a reduction in grazing intensity of overgrazed pastures can lead to an increase in SOC, a reduction in SOC from decreased grazing has also been reported, due to the concomitant reduction in pasture production (Chan et al., 2010). The lack of significant correlation of AGB with either NDVI or SOC illustrates the necessity of using long-term time-series remotely sensed ANPP data, to accurately predict SOC.

SOC did not have any significant correlation with Clay $\%$ for both sampling periods. This finding is attributed to the similarity in clay types and clay fractions across the catchment. The relationship between

Table 2. Results of the Principle Component Analysis for soil attributes, topographical attributes, and ANPP/AGB attributes.

\begin{tabular}{|c|c|c|c|c|c|c|c|c|c|}
\hline \multicolumn{6}{|c|}{2006} & \multicolumn{4}{|c|}{2014} \\
\hline Statistic & PC 1 & $\mathrm{PC} 2$ & PC 3 & $\mathrm{PC} 4$ & PC 5 & PC 1 & PC 2 & PC 3 & PC 4 \\
\hline Eigenvalue & 3.500 & 1.938 & 1.283 & 1.190 & 1.116 & 3.79 & 1.972 & 1.350 & 1.069 \\
\hline$\%$ of Variance & 29.2 & 16.1 & 10.7 & 9.9 & 9.3 & 31.6 & 16.4 & 11.2 & 8.9 \\
\hline Cumulative \% & 29.2 & 45.3 & 56.0 & 65.9 & 75.2 & 34.6 & 48.0 & 59.3 & 68.2 \\
\hline \multicolumn{10}{|l|}{ Eigenvector } \\
\hline SOC & $\underline{0.393}$ & -0.111 & 0.061 & -0.104 & 0.349 & $\underline{0.410}$ & -0.047 & 0.302 & -0.023 \\
\hline Clay \% & $\overline{-0.192}$ & -0.321 & -0.183 & -0.263 & $\underline{-0.570}$ & $\overline{-0.238}$ & 0.335 & 0.190 & 0.335 \\
\hline $\mathrm{pH}^{\circ}$ & -0.266 & 0.087 & 0.536 & -0.379 & $\overline{0.103}$ & -0.284 & -0.278 & 0.259 & 0.284 \\
\hline EC & 0.007 & 0.220 & $\underline{0.564}$ & -0.053 & -0.470 & 0.061 & -0.231 & $\underline{0.679}$ & 0.056 \\
\hline NDVI & $\underline{0.385}$ & 0.278 & 0.296 & -0.006 & 0.105 & 0.306 & $\underline{-0.404}$ & $\overline{0.163}$ & -0.030 \\
\hline AGB & -0.319 & -0.211 & 0.076 & -0.405 & 0.370 & -0.219 & $\overline{0.397}$ & 0.342 & 0.260 \\
\hline Elevation & $\underline{0.372}$ & -0.129 & 0.006 & 0.032 & -0.365 & $\underline{0.394}$ & 0.029 & 0.079 & -0.253 \\
\hline Slope & 0.338 & -0.048 & -0.331 & $\underline{-0.506}$ & -0.052 & $\overline{0.337}$ & -0.019 & 0.014 & 0.408 \\
\hline Aspect & -0.306 & -0.299 & 0.055 & -0.038 & -0.054 & -0.174 & 0.236 & 0.175 & $\underline{-0.596}$ \\
\hline $\begin{array}{l}\text { Profile } \\
\text { Curvature }\end{array}$ & 0.034 & $\underline{0.512}$ & -0.181 & $\underline{-0.504}$ & -0.136 & -0.176 & $\underline{-0.417}$ & -0.357 & 0.218 \\
\hline Plan Curvature & 0.243 & -0.428 & 0.300 & 0.063 & -0.093 & 0.329 & 0.369 & -0.122 & 0.079 \\
\hline TWI & -0.286 & 0.390 & -0.171 & 0.305 & -0.091 & -0.333 & -0.259 & 0.148 & -0.310 \\
\hline
\end{tabular}

Underlined factor loadings are considered highly weighted when within $10 \%$ of variation of the absolute values of the highest factor loading in each PC. 
Kunkel, V. et al., Modelling the Spatial and Temporal Distribution of Soil Organic Carbon

Table 3. Pearson's correlation coefficients between the 12 standardised variables.

\begin{tabular}{|c|c|c|c|c|c|c|c|c|c|c|c|}
\hline 2006 & $\begin{array}{c}\text { SOC } \\
\% \\
\end{array}$ & $\begin{array}{c}\text { Clay } \\
\% \\
\end{array}$ & $\mathrm{pH}$ & $\mathrm{EC}$ & NDVI & $\begin{array}{c}\text { AGB } \\
\% \\
\end{array}$ & $\begin{array}{c}\text { Elevation } \\
(\mathrm{m})\end{array}$ & Slope & Aspect & $\begin{array}{l}\text { Profile } \\
\text { Curv. }\end{array}$ & $\begin{array}{l}\text { Plan } \\
\text { Curv. }\end{array}$ \\
\hline Clay \% & -0.30 & - & & & & & & & & & \\
\hline $\mathrm{pH}$ & -0.30 & 0.12 & - & & & & & & & & \\
\hline $\mathrm{EC}$ & -0.08 & -0.04 & 0.21 & - & & & & & & & \\
\hline NDVI & $0.57 *$ & $-0.48^{*}$ & -0.07 & 0.19 & - & & & & & & \\
\hline AGB & -0.12 & 0.19 & $0.40 *$ & -0.10 & $-0.45^{*}$ & - & & & & & \\
\hline Elevation & $0.44 *$ & -0.01 & $-0.44^{*}$ & 0.12 & $0.48 *$ & -0.38 & - & & & & \\
\hline Slope & $0.47 *$ & 0.00 & -0.34 & -0.10 & 0.25 & -0.20 & 0.38 & - & & & \\
\hline Aspect & -0.26 & 0.32 & 0.19 & -0.02 & $-0.41^{*}$ & $0.53 *$ & -0.09 & -0.29 & - & & \\
\hline $\begin{array}{l}\text { Profile } \\
\text { Curv. } \\
\text { Plan }\end{array}$ & -0.09 & -0.07 & 0.14 & 0.12 & 0.24 & -0.09 & -0.03 & 0.31 & -0.28 & - & \\
\hline Curv. & 0.33 & 0.09 & -0.06 & -0.03 & 0.15 & -0.22 & 0.31 & 0.16 & -0.13 & -0.37 & - \\
\hline TWI & -0.39 & 0.02 & 0.08 & 0.06 & -0.18 & 0.02 & -0.35 & $0 . \overline{4} 5^{*}$ & 0.17 & 0.23 & $-0.54 *$ \\
\hline 2014 & $\begin{array}{c}\text { SOC } \\
\% \\
\end{array}$ & $\begin{array}{c}\text { Clay } \\
\%\end{array}$ & $\mathrm{pH}$ & $\mathrm{EC}$ & NDVI & $\begin{array}{c}\mathrm{AGB} \\
\%\end{array}$ & $\begin{array}{c}\text { Elevation } \\
\text { (m) }\end{array}$ & Slope & Aspect & $\begin{array}{l}\text { Profile } \\
\text { Curv. }\end{array}$ & $\begin{array}{l}\text { Plan } \\
\text { Curv. }\end{array}$ \\
\hline Clay $\%$ & -0.34 & - & & & & & & & & & \\
\hline $\mathrm{pH}$ & -0.38 & 0.21 & - & & & & & & & & \\
\hline EC & 0.33 & -0.11 & 0.21 & - & & & & & & & \\
\hline NDVI & $0.64 *$ & $-0.45^{*}$ & -0.05 & 0.30 & - & & & & & & \\
\hline AGB & -0.24 & $0.57 *$ & 0.14 & 0.02 & $-0.50^{*}$ & - & & & & & \\
\hline Elevation & $0.63 *$ & -0.31 & $-0.44 *$ & 0.06 & $0.51 *$ & -0.36 & - & & & & \\
\hline Slope & $0.52 *$ & -0.16 & -0.25 & 0.11 & 0.37 & -0.23 & $0.44 *$ & - & & & \\
\hline $\begin{array}{l}\text { Aspect } \\
\text { Profile }\end{array}$ & -0.23 & 0.24 & 0.02 & -0.06 & -0.35 & 0.22 & -0.06 & -0.32 & - & & \\
\hline $\begin{array}{l}\text { Curv. } \\
\text { Plan }\end{array}$ & -0.36 & -0.07 & 0.31 & -0.07 & 0.07 & -0.27 & -0.37 & -0.09 & -0.18 & - & \\
\hline Curv. & $0.43 *$ & -0.11 & $-0.64 *$ & -0.08 & 0.03 & -0.03 & 0.43 & 0.36 & -0.17 & $-0.46^{*}$ & - \\
\hline TWI & $-0.44 *$ & 0.09 & 0.33 & 0.16 & -0.14 & 0.10 & $-0.47 *$ & $\begin{array}{c}- \\
0.55^{*} \\
\end{array}$ & 0.21 & 0.31 & $-0.67 *$ \\
\hline
\end{tabular}

NDVI and clay was moderate and negative. For areas in the catchment that receive higher precipitation, finer textured soils may become waterlogged more frequently and thereby inhibit root growth, and thus inhibit allocation of $\mathrm{C}$ belowground (McSherry and Ritchie, 2013). NDVI also had negative correlations (significant negative correlation, $\mathrm{p}<0.01$ in 2006) with aspect, where north-facing slopes had lower levels of ANPP. By association, SOC also had similar relationships with aspect, although the relationships were weaker. This indicates that some environmental factor is affecting SOC, such as temperature, but not affecting NDVI.

Linear regressions analyses for the variables that had the strongest correlations with SOC are shown in Figure 3. Performing the Goldfeld-Quant test for heteroscedasticity for those correlations showed that the relationships were homoscedastic (e.g. SOC-NDVI 2014: F(13,13) crit, $0.1 \%=3.70)$.
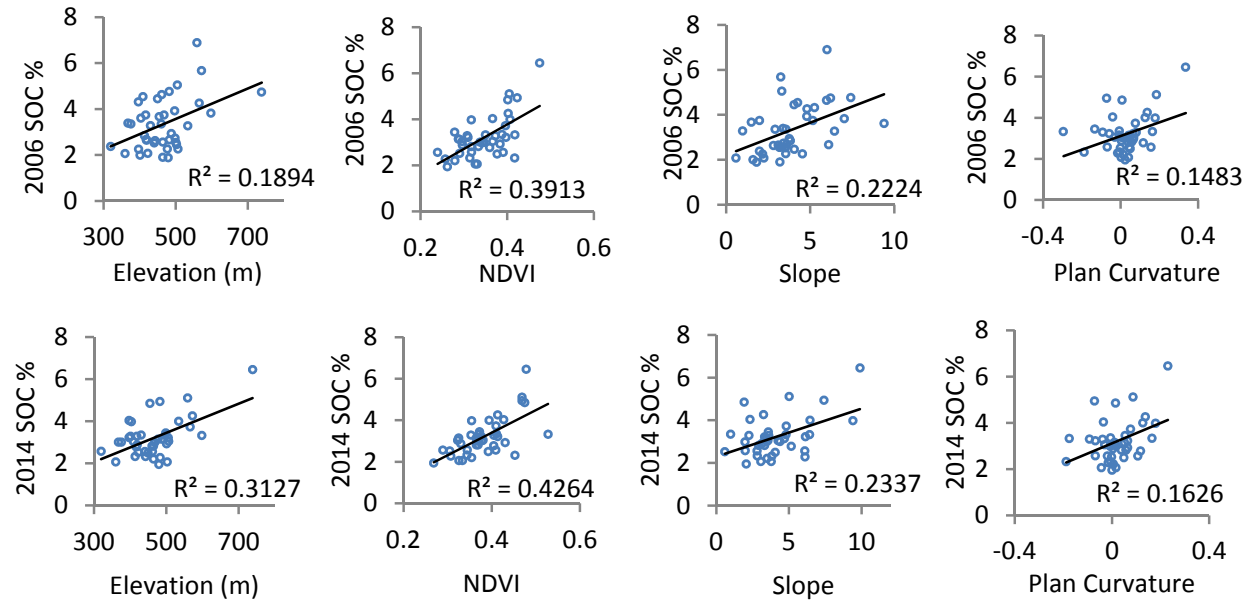

Figure 3. Linear regressions of SOC with elevation, NDVI, slope, and plan curvature for 2006 and 2014. 


\section{DISCUSSION AND CONCLUSIONS}

Due to the inherent spatiotemporal heterogeneity of SOC, directional changes in SOC require long term sampling periods (Post et al., 2001). The results of this study show that soil carbon was temporally stable over medium time scales ( $8+$ years), assuming that there were no fluctuations in SOC between the two sampling periods. The relationship between SOC and NDVI was also temporally stable, with strong, positive and significant correlations found between SOC and NDVI for both sampling periods. 2014 had a slightly stronger positive SOC-NDVI correlation $(r=0.64)$ than $2006(r=0.56)$. Grazing intensity was shown to have little influence on the distribution of SOC for both sampling periods.

Strong, positive correlations have been found previously between SOC and vegetation indices at larger scales (e.g. $>1 \times 10^{\wedge} 6 \mathrm{~km}^{\wedge} 2$, Yang et al. 2008). Precipitation is the primary influence on NDVI, where precipitation is itself influenced by topography. Topographical attributes, such as elevation, determines the microclimate and thus large spatial distribution and patterns of vegetation (Jin et al. 2008). In this study, NDVI was observed to have significant correlations with elevation. In turn, SOC had strong correlations with elevation. However, the relationships between SOC and elevation, and NDVI and elevation, were not consistent with each other. In 2006, NDVI had a slightly stronger correlation with elevation $(r=0.48)$ than did SOC $(r=$ $0.44)$. For 2014 , the situation was reversed, with elevation having the stronger relationship with SOC $(\mathrm{r}=$ $0.63)$ than with NDVI $(r=0.51)$. Thus, there are long term seasonal variables influencing net primary production and SOC in different ways. This implies that, although SOC can be predicted using both NDVI and elevation, other climate factors may need to be considered, such as temperature, which may have a larger influence on SOC than on ANPP.

Seasonal differences in climate may also affect the influence of different topographical attributes on NDVI, and, in turn, on SOC. After elevation, it was the variables of slope and aspect that had the strongest (although still relatively weak) correlations with NDVI for both sampling periods, with aspect having a significant negative correlation with NDVI in 2006 (north-facing slopes had less ANPP), but not significant in 2014. This temporal difference for the aspect-NDVI relationship is attributed to seasonal changes in rainfall between 2006 and 2014. However, despite the weak to moderate relationship between aspect and NDVI, this was not reflected in the relationship between SOC and aspect, again indicating that other variables influence SOC more strongly than ANPP. The apparent influence of slope and aspect, as well as elevation, on ANPP is attributed to the relatively narrow range of elevations $(\sim 300-\sim 1100 \mathrm{~m})$ of the Krui catchment.

The spatial and long term temporal stability of SOC at the catchment scale demonstrated in this study has major implications for soil carbon sequestration. SOC across the catchment appears to be at equilibrium, with minimal variation observed after 8 years. This has important implications for carbon sequestration, where significant changes to catchment average SOC may require observations over time scales much greater than 8 years. However, SOC may have fluctuated between the intervening years between samples. Improvement of this study would involve frequent (annual) sampling of the same locations for 2-3 years.

\section{REFERENCES}

Bevan, K. J. \& Kirkby, M. J. (1979). A physically bases, variable contributing area model of basin hydrology. Hydrological Society Bulletin 24(43-69).

Chan, K. Y., Oates, A., Li, G. D., Conyers, M. K., Prangnell, R. J., Poile, G., Liu, D. L. \& Barchia, I. M. (2010). Soil carbon stocks under different pastures and pasture management in the higher rainfall areas of south-eastern Australia. Soil Research 48(1): 7-15.

Dorji, T., Odeh, I. O. A., Field, D. J. \& Baillie, I. C. (2014). Digital soil mapping of soil organic carbon stocks under different land use and land cover types in montane ecosystems, Eastern Himalayas. Forest Ecology and Management 318: 91-102.

Luo, Z., Wang, E. \& Sun, O. J. (2010). Soil carbon change and its responses to agricultural practices in Australian agro-ecosystems: A review and synthesis. Geoderma 155(3-4): 211-223.

McSherry, M. E. \& Ritchie, M. E. (2013). Effects of grazing on grassland soil carbon: a global review. Global Change Biology 19(5): 1347-1357.

Rüdiger, C., Hancock, G., Hemakumara, H. M., Jacobs, B., Kalma, J. D., Martinez, C., Thyer, M., Walker, J. P., Wells, T. \& Willgoose, G. R. (2007). Goulburn River experimental catchment data set. Water Resour. Res. 43(10): W10403.

Schimel, D., Stephens, B. B. \& Fisher, J. B. (2015). Effect of increasing CO2 on the terrestrial carbon cycle. Proceedings of the National Academy of Sciences 112(2): 436-441.

Yang, Y. H., Fang, J. Y., Tang, Y. H., Ji, C. J., Zheng, C. Y., He, J. S. \& Zhu, B. A. (2008). Storage, patterns and controls of soil organic carbon in the Tibetan grasslands. Global Change Biology 14(7): $1592-$ 1599. 